\title{
1 Firn Permeability Impacts on Pressure Loss Associated with Rapid Air 2 Movement Drilling
}

$3 \quad$ A. N. Whelsky ${ }^{1}$, M. R. Albert ${ }^{1}$

$4 \quad[1]$ Thayer School of Engineering, Dartmouth College, Hanover, NH 03766

5 Correspondence to: A. N. Whelsky (Amber.N.Whelsky.TH@dartmouth.edu)

$6 \quad$ Key Points

7 - The layered nature of firn may include high-permeability bands that impact the performance of $8 \quad$ an air-drill system.

- Borehole pressure loss is highest in firn that has bands of higher air permeability layers.

- Results indicate that the presence of higher-permeability layers near the bottom of the borehole would most directly lead to pressure loss large enough to impede drilling.

\section{Abstract}

13 The polar ice sheets of Greenland and Antarctica are sensitive indicators of weather and climate, and also

14 serve as natural archives of past climate; evidence from within and below the ice is important for

15 scientific investigations. A variety of ice drilling techniques have been used for a wide array of scientific

16 applications, including mechanical ice coring, hot water drilling of access holes, and compressed air-

17 drilling of holes to contain explosive charges for seismic measurements. Creating access holes using

18 compressed air-drilling in ice has rapid rates of penetration in some locations on an ice sheet, yet the

19 technique has failed at shallower depths in other locations. This paper investigates the interaction of the

20 properties of the aged snow, called 'firn', with pressure loss associated with compressed air-drilling.

21 Specifically, we report on numerical studies examining the impact of firn layering and firn permeability

22 on air-drill induced pressure changes inside the borehole and in the surrounding firn. Results indicate

23 borehole pressure loss is highest in firn that has bands of higher air permeability layers. A loss of

24 borehole pressure would lead to decreased ice-chip air transport up through the borehole, causing

25 degraded drill performance as ice chips clog the drill bit, stalling the drill. Numerical results show that 
the presence of higher-permeability layers near the bottom of the borehole may lead to sufficient pressure

27 loss to impede drilling. In contrast to other kinds of ice drilling, where casing the borehole near the

28 surface is common, casing the bottom of the borehole may be necessary for rapid air movement drilling in 29 areas where high permeability bands of layers exist at depth.

\section{Keywords}

31 Ice sheet, drilling, firn properties, permeability.

\section{Introduction}

33 The polar ice sheets of Greenland and Antarctica are sensitive indicators of weather and climate, and also serve as natural archives of past climate. In the cold, high central regions of the ice sheets where the snow seldom melts, the glacial ice is multiple kilometers thick. With annual snowfall accumulation rates on the order of centimeters, the top approximately $60-120 \mathrm{~m}$ of the ice sheet consists of aged porous snow called

37 'firn'; at greater depths, the firn has been compacted to solid ice. A variety of ice drilling techniques are used for various scientific purposes on the ice sheets. For example mechanical ice coring is used for retrieving ice cores for climate records; hot water drills are used for creating access holes for subglacial sampling; air-drills using compressed air create holes for seismic measurements of ice sheet

41 characteristics. Creating access holes using compressed air-drilling in ice has shown rapid rates of

42 penetration in some locations on an ice sheet, yet the drill can stall at shallower depths in other locations.

43 For example, air-drilling campaigns have successfully drilled to $90 \mathrm{~m}$ depth at sites in West Antarctica

44 (Bolsey, R., 2009), yet the same drill has stalled at approximately $63 \mathrm{~m}$ at the South Pole Station in East 45 Antarctica (Jayred, M., 2011).

47 earth or polar firn, relies on understanding forced fluid flow in a channel through the porous media.

48 Beavers and Joseph (1967) examined free flow of a Newtonian fluid past a saturated permeable block in 
order to understand boundary region interactions occurring at the open channel-porous media interface at

50 Reynolds numbers less than 100. They found that a boundary layer exists within the porous media due to

51 viscous shear effects. Both Berman (1953) and Granger et al. (1989) presented analytical solutions of

52 laminar flow through a rectangular channel through porous media associated with their studies of

53 microfiltration systems. Granger also extended the study to investigate laminar flow in a cylindrical

54 channel. Both studies found that pressure and velocity profiles decrease along the flow direction,

55 especially in situations where the walls have a higher permeability. For higher velocity flows, Olson and

56 Eckert (1966) experimentally tested turbulent air flow ( $\operatorname{Re}$ on the order of $\left.10^{4}\right)$ through a porous tube in a

57 situation involving injection of air through the porous wall for transpirational cooling. They found that

58 most changes in flow parameters, including momentum flux, occurred within the initial entrance length of

59 10-12 tube diameters. With respect to drilling applications, where there is a high Re flow in an open

60 cylindrical channel through a porous material without injection along the wall, there is a lack of

61 published information about the effect of permeable formations on drilling efficiency, despite numerous

62 applications including oil extraction, ground water extraction, underground storage, and scientific

63 investigations.

64

Rotary drilling technology using compressed air or other gases as the circulation fluid has long

65 been used in the petroleum industry. In drilling through rock, air as the circulating fluid has several

66 advantages over hydraulic drilling, including a greater drilling speed as well as a smaller likelihood of

67 causing formation damage, which is crucial in optimizing well production in oil and gas recovery projects

68 (Nicolson, 1953; Lyons et al., 2009). The use of compressed air-drilling for creating access holes in an ice

69 sheet has long supported important geophysical discoveries about ice sheets and ice sheet behavior. For

70 example, air-drilling enabled the seismic records of englacial seismic reflectivity at the bottom of the ice

71 sheet at several sites in West Antarctica including WAIS Divide and Thwaites Glacier (Horgan et al.,

72 2011). The Ice Drilling Design and Operations group of the U.S. Ice Drilling Program (www.icedrill.org)

73 currently uses an air-drill, the Rapid Air Movement (RAM) drill for creating access holes in the ice sheet. 
74 The RAM drill uses compressed air to drive rotating cutters for penetration in polar firn, and it has 75 successfully drilled to approximately 90 meters depth at various sites across the West Antarctic Ice 76 Sheet, but was unable to penetrate past approximately 63 meters when used at the South Pole on the East 77 Antarctic Ice Sheet. The cause of drill failure has been unclear. No measurements of firn permeability 78 exist at any of the drill sites where the RAM drill has been used.

For any porous material, intrinsic permeability is the material property that is proportional to the ratio of the pressure drop in the flow direction to the fluid flow rate through the material. On the polar ice

81 sheets, regional differences in environmental conditions such as snow accumulation rate and ambient

82 temperature play an important role in the development of the physical properties, including permeability

83 of layered snow and firn (Albert et al. 2004; Courville et al., 2007; Horhold et al., 2009; Gregory et al.,

84 2014). This paper presents results of numerical finite element experiments to investigate the effects of firn

85 permeability on forced air flow through a cylindrical channel in the firn associated with a borehole air-

86 drill system. We do not aim to model the mechanics of the RAM drill mechanical components in this

87 study, due to a lack of any information on the firn parameters with depth at the locations where the drill

88 has been used. Instead, the goal is to investigate the nature of pressure changes in the borehole and in the

89 surrounding layered firn under pressure forcing conditions that would be induced by a pneumatic drill, in

90 effort to better understand the impact that the permeability of the firn could have on rapid air-drilling.

The East Antarctic plateau generally exhibits lower accumulation rates and colder average

92 temperatures when compared with sites in West Antarctica or on the Greenland ice sheet. The South Pole,

93 East Antarctica, for example, has a mean annual temperature of $-51^{\circ} \mathrm{C}$ and accumulation rate of $8 \mathrm{~cm}$ ice-

94 eq $\mathrm{yr}^{-1}$ (e.g. Severinghaus et al., 2001). In contrast, the WAIS Divide site in West Antarctica and Summit,

95 Greenland are both warmer and receive more annual snowfall, with mean annual temperatures of $-31^{\circ} \mathrm{C}$

96 and $-31.4^{\circ} \mathrm{C}$ and $22 \mathrm{~cm}$ ice-eq $\mathrm{yr}^{-1}$ and $23 \mathrm{~cm}$ ice-eq $\mathrm{yr}^{-1}$ respectively (Severinghaus et al., 2010;

97 Schwander et al., 1993). Lower accumulation areas tend to coincide with more permeable firn compared

98 to higher accumulation sites due to an increased snow crystal residence time at the surface; resulting in 
prolonged exposure to temperature gradients causing snow metamorphism in near surface firn (Rick and Albert, 2004, Albert et al., 2004; Courville et al., 2007, Horhold, Albert and Freitag, 2009). Near-surface temperature gradients are caused by diurnal and seasonal temperature swings, with the strongest

102 gradients, due to diurnal changes, existing in the top $20 \mathrm{~cm}$ (e.g. Brandt and Warren, 1997). The near-

103 surface temperature gradients induce differences in vapor pressure within the snow and firn that drive firn 104 grain metamorphism. This temperature-driven metamorphism favors the growth of large crystals while 105 small crystals sublimate (e.g. Colbeck, 1983), leading to larger interstitial pore spaces (Albert et al., 2004; 106 Flanner and Zender, 2006).

107 Measurements of firn layering and permeability exist from firn cores drilled in West Antarctica (Albert et 108 al 2000; Rick and Albert, 2004), at Summit, Greenland (Adolph and Albert, 2014), at Megadunes in East 109 Antarctica (Courville et al, 2007), and at WAIS Divide in West Antarctica (Gregory et al., 2014).

110 Unfortunately there have not been any permeability measurements made at sites where the RAM drill has 111 been used. In this paper, we use measured permeabilities to establish bounds for numerical experiments 112 to investigate the impact of discrete depths of high and low permeability anomalies on the impact of 113 borehole pressure differences and air flow in the surrounding firn. Anomalous bands of higher 114 permeability have been recorded in firn in past literature. Specifically, Rick and Albert (2004) discuss the 115 impact of accumulation rate and temperature on the development of microstructure, affecting the 116 permeability of one meter-scale thickness bands in the firn. They examine multiple scenarios of different 117 climate conditions that would explain a highly connected pore volume, leading to a high permeability 118 anomaly, seen at 12 meters depth on a firn core extracted from West Antarctica. They discovered that, at 119 the site investigated, a short term climatic event led to a short residence time that affected pore space and 120 permeability in a band of firn near 12 meters depth. 


\section{Theory}

124 This study investigates multidimensional air flow, forced by higher pressure at depth in a borehole, up the 125 annular region of the borehole and also laterally out from the borehole into the porous firn. The numerical 126 simulations are single-phase flow (air); multi-phase aspects of the combined air flow and ice chip

127 transport that exist with the drill system (a multiphase mixture of air and ice chips) are beyond the scope 128 of the current study. By assuming an ice chip diameter of $5 \mathrm{~mm}$, we can calculate the force due to gravity 129 pulling the chip down to be about $6 \times 10^{-4} \mathrm{~N}$. This weight is much less than the force applied due to dynamic pressure exerted on the surface of the ice chip as a result of air, with a density of $1.4 \frac{\mathrm{kg}}{\mathrm{m}^{3}}$ moving

131 at $0.38 \frac{\mathrm{m}^{3}}{\mathrm{~s}}$ through an annular area of $0.01 \mathrm{~m}^{2}$, with an approximate force of $1000 \mathrm{~N}$. Thus we focus on 132 single phase-air flow and resulting pressure changes in the annular cavity and in the surrounding porous 133 firn. For the single phase steady state problem, the Navier-Stokes equations describing momentum and mass conservation of a compressible gas in an open (non-porous) channel are as follows (Kundu, 2012):

$$
\begin{gathered}
\rho(\vec{u} \cdot \nabla \vec{u})=-\nabla p+\eta \nabla^{2} \vec{u}+\left(\eta_{v}+\frac{1}{3} \eta\right) \nabla(\nabla \cdot \vec{u})+\boldsymbol{F} \\
\nabla(\rho \vec{u})=0
\end{gathered}
$$

135 Here $\vec{u}$ is fluid velocity vector $(\mathrm{m} / \mathrm{s}), \eta$ is dynamic viscosity $(\mathrm{Pa} \cdot \mathrm{s}), p$ is pressure $(\mathrm{Pa}), \eta_{v}$ is the coefficient 136 of bulk viscosity, $\mathbf{F}$ is a body force matrix such as gravity and $\rho$ is fluid density $\left(\mathrm{kg} / \mathrm{m}^{3}\right)$. Within the 137 porous media (firn), Darcy's equation describes the flow with an added Brinkman term to account for 138 fluid viscous effects (Guta and Sundar, 2010):

$$
\begin{gathered}
\frac{\eta}{\kappa} \vec{u}=-\nabla p+\frac{\eta}{\varepsilon_{p}} \nabla^{2} \vec{u}+\frac{1}{\varepsilon_{p}}\left(\eta_{v}+\frac{1}{3} \eta\right) \nabla(\nabla \cdot \vec{u})+\boldsymbol{F} \\
\nabla(\rho \vec{u})=0
\end{gathered}
$$


The inlet condition is established using air flow rate measurements taken during an air-drill (RAM drill)

141 field project at the South Pole, East Antarctica. The maximum volumetric flow rate entering the borehole

142 was recorded to be approximately $0.38 \frac{\mathrm{m}^{3}}{\mathrm{~s}}$ (800 SCFM) (Benson, pers comm 2014). Dividing by the cross

143 sectional area of $0.01 \mathrm{~m}^{2}\left(0.11 \mathrm{ft}^{2}\right)$ of the annular space, the resulting Mach number is approximately 0.12

144 for air temperature of $-31.4^{\circ} \mathrm{C}$, which is well within the regime of subsonic flow. Hence the fluid flow

145 calculations involves incompressible flow conditions.

\section{Boundary Conditions}

147 The geometry of the problem is 3D axisymmetric, with boundary conditions along the two walls of the 148 concentric cylindrical geometry of the borehole, plus boundary conditions laterally along the snow 149 surface of the top boundary, laterally at depth below the bottom of the borehole, and vertically through 150 the firn at large distance from the borehole. Figure 1 depicts the geometry of the problem. The inside 151 wall of the annulus, at the drill line interface, is set to have a no-slip boundary condition. The outside wall 152 of the annulus is along the borehole interface between the air in the borehole and the surrounding firn. At 153 this interface, continuity of the air flow velocity field and pressure are enforced. The outer vertical edges 154 of the computational domain for the firn, far from the borehole, as well as the lateral boundary along the 155 snow surface at the top of the annulus and surrounding firn allow air to escape with pressure under 156 hydrostatic conditions:

$$
\rho_{\text {firn matrix }}=\left(g \rho_{\text {firn }}+g \rho_{\text {pore air }}\right) z
$$

157 Where $g \rho_{\text {firn }}$ and $g \rho_{\text {pore air }}$ are the weight per unit volume of the ice in the firn and air contained in 158 pore space above depth $z$. All pressures in the borehole-firn system in this model are gage pressure 159 readings, therefore the pressure boundary condition horizontally along the snow surface $(\mathrm{z}=0)$ will be 160 defined as zero. 
161 The inlet air flow forcing this system is set at the bottom of the borehole, for simulating air velocity and

162 pressure drop along the direction of flow up the annulus and also out into the surrounding firn. Pressure

163 drop through the drill head is neglected. Bottom borehole pressure is assumed to be a combination of

164 hydrostatic pressure, due to the weight of the air column inside the borehole, plus the pressure

165 contribution from three air compressors that were run in parallel, rated at $0.19 \frac{\mathrm{m}^{3}}{\mathrm{~s}}(400 \mathrm{SCFM}), 1.28 \times 10^{6}$

$166 \mathrm{~Pa}$ (200 psig), forcing air out of the drill line into the bottom of the borehole (Benson, pers comm 2014).

167 The inlet pressure contribution in this model is approximately $1.03 \times 10^{6} \mathrm{~Pa}(150 \mathrm{psig})$, based on measured 168 readings from a gage downstream of the three compressor assembly during a field campaign with the 169 RAM drill (Benson, pers comm 2014).

170 Methods

\section{The Model}

172 The snow surface exists laterally radiating out from $\mathrm{r}=0 \mathrm{~m}$ to $\mathrm{r}=10 \mathrm{~m}$, and the modeled vertical region 173 extends from $\mathrm{z}=0 \mathrm{~m}$ to $\mathrm{z}=-80 \mathrm{~m}$ depth in the firn (Figure 1). The open air space in the borehole extends 174 from $r=0.027 \mathrm{~m}(1.05 \mathrm{in})$ to $\mathrm{r}=0.064 \mathrm{~m}(2.5 \mathrm{in})$, and the bottom of the borehole is at $\mathrm{z}=-40.5 \mathrm{~m}$. The 175 pressure condition at the bottom of the borehole is set at $0.027 \mathrm{~m}<\mathrm{r}<0.064 \mathrm{~m}, \mathrm{z}=-40.5 \mathrm{~m}$. The left-hand 176 figure in Figure 1 shows the two-dimensional velocity vector field caused by air entering the bottom of 177 the borehole, within the firn column, where it can be seen that the greatest magnitude of air velocity 178 escaping into the firn is near the bottom of the borehole. At distances farther from the bottom of the 179 borehole, the air flow slows due to viscous forces. The right-hand diagram of Figure 1 is a close-up view 180 of the annular space and firn geometry. The multidimensional axisymmetric problem is solved by the 181 finite element method, using COMSOL Multiphysics ® software.

182 Permeability is prescribed as a function of depth in the model through use of a nonlinear, least-squares 183 regression fits to existing permeability data: 


$$
\mathrm{e}^{-0.077 \mathrm{z}+3.9} \times 10^{-10} \mathrm{~m}^{2}
$$

185 Where $\mathrm{z}$ is depth $(\mathrm{m})$.

186 The nonlinear fit results from regression curve-fitting to firn core permeability data from Summit,

187 Greenland (Adolph and Albert, 2014), a site with generally moderate firn permeability. Note that this fit

188 does not replicate all of the variability that occurs across length scales in the firn column, but the fit is

189 useful for model investigations of the impact of the overall permeability trends on air-drill interaction

190 with the surrounding firn.

\section{$191 \quad$ Numerical Experiments}

192 Firn is a naturally-deposited layered, inhomogeneous medium, with individual snow precipitation events

193 forming layers that are distinguished by microstructural differences that affect the permeability. The

194 points plotted in Figure 2 show measured firn permeability as a function of depth (Adolph and Albert,

195 2014) from Summit, Greenland. The continuous, smooth curve in bold through the points is the line

196 produced by regression curve fitting to the data; the equation for the fit is given in Eq. 1. In addition,

197 boxes are drawn in solid lines at eight different depths along the curve in Figure 2 that illustrate a

198 difference of approximately one standard deviation from the mean value over that meter of firn (each box

199 is shown as one meter in thickness). For use in numerical experiments, the boxes indicated by the solid

200 lines impose a hypothesized anomalous permeability band, or group of adjacent layers which have a

201 distinctly higher permeability than mean value of the curve fit at that depth. These boxes have been

202 chosen so that the permeability of the hypothetical one-meter band would fall within the spread of the

203 measured data near that depth. For the boxes, the eight different depths are listed in Table 1, along with

204 the mean and one standard deviation of permeability for each depth range. 
Table 1 One standard deviation from mean permeability at given depth

\begin{tabular}{c|ccc}
\hline Trial & $\begin{array}{c}\text { Depth of Hypothesized } \\
\text { permeability anomaly }(\mathrm{m})\end{array}$ & $\begin{array}{c}\text { Mean permeability from the } \\
\text { curve fit }\left(\mathrm{x} 10^{-10} \mathrm{~m}^{2}\right)\end{array}$ & $\begin{array}{c}\text { One Standard Deviation from } \\
\text { Mean Value of permeability } \\
( \pm)\left(\mathrm{x} 10^{-10} \mathrm{~m}^{2}\right)\end{array}$ \\
\hline 1 & $5-6$ & 41.1 & 20.3 \\
3 & $10-11$ & 27.0 & 7.5 \\
4 & $15-16$ & 15.9 & 3.8 \\
5 & $20-21$ & 9.8 & 2.1 \\
6 & $25-26$ & 9.0 & 3.1 \\
7 & $30-31$ & 4.4 & 1.6 \\
8 & $35-36$ & 3.7 & 1.5 \\
\hline
\end{tabular}

\section{Numerical Study 1}

In order to evaluate the effect of permeability on air pressure within the borehole and also in the firn surrounding the borehole, the model was first run at steady state with borehole depth held at 40.5 meters;

211 the firn thickness was held at 80 meters (approximate distance to lock in-depth at Summit, Greenland

212 (Faïn et al., 2009)), and the boundary condition on pressure at the bottom of the borehole was prescribed 213 to be $1.28 \times 10^{6} \mathrm{~Pa}$, in accordance with measurements from the drill operation as described above. In all 214 numerical experiments, the pressure profiles from the bottom of the borehole up to the surface along the 215 center of the annular cavity, as well as at one meter distance from borehole in the firn, will be plotted. In 216 the first numerical study, the model was run for three numerical experiments, one with firn permeability 217 following the exponential decay trend of the permeability site, seen in Figure 2, and two numerical 218 experiments that vary the permeability in only the section of firn extending from $40-41$ meters depth.

219 The altered permeability was raised in one experiment and lowered in the other, in magnitude equal to one standard deviation from the mean. Thus the hypothesized band of higher or lower permeability is still 
221 within the range of measured permeability in that depth range. Results from these experiments are

222 graphed in Figure 3. Figures 3a and 3c show permeability of modeled firn as a function of depth in each

223 experiment. Figures $3 b$ and $3 d$ shows pressure calculated at a one meter radial distance from the annulus.

224 A region of higher permeability firn surrounding the bottom of the borehole leads to an increase in

225 pressure in the firn at the one meter radial distance from the borehole, as more air is able enter the porous

226 matrix as compared to the other two cases (no-anomaly and low-permeability anomaly). Figure 3e shows

227 the pressure along a line at the center of the annular cavity, running from 35m depth down to the bottom

228 of the borehole at $40.5 \mathrm{~m}$ depth. The existence of a high permeability anomaly inside the firn (dotted line)

229 causes the most loss of pressure inside the borehole when compared to the no-anomaly and low-

230 permeability anomaly experiments (solid and dashed lines respectively). The pressure decreases from the

231 bottom of the borehole to the top, as expected.

\section{Numerical Study 2}

233 The second numerical study investigates the impact of the depth of the permeability anomaly on the

234 resulting pressure profiles and pressure loss over the entire borehole. The borehole depth was again fixed

235 at 40.5 meters and the depth of the permeability anomaly for each trial is given in Table 1 . The simulated

236 permeability of the anomaly was adjusted in the model to be one standard deviation higher than the

237 average of the measured values located at each depth for which the simulated anomaly was placed. The

238 average of the permeability measurements around the depth of the anomaly, and the simulated

239 permeability of the anomaly is also presented in Table 1. The results, plotted in Figure 4, indicate that the

240 location of a simulated permeability anomaly on an air-drilling system does have an effect on the pressure

241 gradient within the firn surrounding the borehole. Figure 4a shows the calculated pressure in the firn at a

242 one-meter radial distance from the borehole. Two of the eight trials are shown, one (solid line) where the

243 permeability anomaly is placed at depth $35-36 \mathrm{~m}$, and another (dotted line) where the permeability

244 anomaly is placed at depth $40-41 \mathrm{~m}$. The Figure $4 \mathrm{~b}$ shows the results of vertically-integrating the pressure

245 profiles (two examples are given in Figure 4a) for all eight trials, where the $\mathrm{x}$ axis indicates depth of the 
top of the permeability anomaly. The total pressure, from air entering the firn porous matrix along the

247 borehole, is calculated to be highest when the permeability anomaly is located at the bottom of the 248 borehole (between 40-41m), where air is first entering the annular space. Figure 4c shows the radial

249 pressure difference as a function of depth for each trial. The radial differential pressure, taken from center 250 of the annulus to a lateral distance of one meter in the firn at that depth, is greater when the anomaly is 251 located at the bottom of the borehole than in cases where it is closer to the snow surface, in spite of the 252 fact that the permeability of the firn increases in the direction toward the surface. By Darcy's law, for a 253 given permeability, the larger differential pressure gradient will drive a higher volumetric flow rate of air 254 into the firn. The potential largest loss of air is thus at the bottom of the borehole where the largest 255 differential pressure exists between the borehole and the surrounding firn. Above this depth, the pressure 256 inside the borehole decreases, leading to a lower differential pressure at any given depth between the 257 borehole and the surrounding firn. The lowered borehole pressure leads to less air loss into the firn, in 258 spite of the fact that the permeability is higher in the anomalous bands closer to the surface.

\section{Discussion}

260 The two numerical studies described above examined the pressure effects that arise from a one-meter

261 thick simulated permeability anomaly in the firn. Because the hypothesized one-meter thick permeability

262 anomaly in the modeled firn is within the variance of measured permeability found within a one meter 263 region, these simulations are not out of the realm of possibility of occurrence even under normal conditions of firn structure.

265 Pressure conditions in the borehole are important to air drill performance. We have shown that the 266 pressure profile within the annulus and firn is sensitive to firn permeability, which can vary considerably 267 under natural climate conditions between different geographical sites. Within the last two decades, 268 microcomputed tomography $(\mu \mathrm{CT})$ has become integrated into polar research to improve understanding 269 of microstructural changes that happen within the snowpack and firn in the polar regions (Flin et al., 
2003; Schneeblei and Sokratov, 2004; Freitag et al., 2004; Lomonaco et al., 2011; Gregory et al., 2014).

Gregory et al. (2014) have shown that porosity is a poor indication of permeability because it does not account for the tortuosity and connectivity of the pore structure. Therefore, without direct measurements of permeability with depth, it is difficult to apply our model to another site with different site characteristics to determine pressure effects within the borehole. However by integrating the permeability during each of the eight trials examined in Numerical Study 2 above, where the higher permeability anomaly was moved to various depths, and comparing that integrated permeability with differential pressure inside the borehole, we demonstrated that the way the permeability changes with depth is critical when considering pressure effects within the borehole. Figure 5 shows a plot of the depth of the anomalous band during each of the eight experiments against the corresponding differential pressure within the borehole during each experiment (grey dots) as well as against the corresponding integrated permeability of the firn column (black dots). Since the anomaly increases the permeability of the firn at some location, all eight trials show an increase in integrated permeability as compared to the trial where no anomaly exists as would be expected (at point zero on the x-axis). The integrated permeability is marginally higher when the anomaly exists in the top ten meters. This result is expected, as the anomaly is raising the permeability where firn typically is the most permeable (refer to Figure 2). The differential pressure remains near a constant value, except in the case when the permeability anomaly is located near the bottom of the borehole. In that case the immediate loss of mass lowers the bottom hole pressure, and hence the differential pressure between the bottom and top of the borehole. This differential pressure is critical for proper drilling as it is the main driving force behind chip removal from the bottom of the borehole. Loss of differential pressure can result in clogging of the drill bit, leading to inability for the drill to continue to operate. It is evident that the impact of air loss from the borehole to the firn, affecting differential pressure within the borehole, is most sensitive to permeability anomalies at the bottom of the borehole, where compressed air first enters the annular space. Thus, in contrast to usual assumptions about borehole casings, casing near the bottom of the borehole could have a bigger impact on air-drill performance than casing near the top. 


\section{Conclusion}

297 This study demonstrates that the firn permeability-depth profile has significant impact on air loss from the

298 borehole of an air-drill system. Air loss through the interconnected porous space of the firn results in a

299 decrease in pressure inside the borehole as well as an increase in pressure in the surrounding firn at a

300 given depth. Pressure loss effects due to firn permeability were found to be most sensitive near the bottom

301 of the borehole, where compressed air of highest pressure first enters the annular space. The immediate

302 loss of bottom hole pressure directly leads to a loss in total differential pressure inside the borehole. This

303 differential pressure is essential for proper chip ejection as it is what helps drive air with the loose snow

304 and ice chips up to the surface. In contrast to previous assumptions that a remedy to air-drill failure might

305 be to case the top of the borehole, these results indicate that a potential solution to mitigate the loss of

306 differential pressure is to case the near bottom of the borehole, at depths near the drill head, to prevent air

307 flow and pressure loss to the surrounding firn where the highest radial differential pressure exists.

\section{Acknowledgements}

309 We thank Mike Jayred and Terry Benson for providing information regarding the performance of US Ice

310 Drilling Program's RAM Drill. This project was funded as part of the NSF grant PLR-1327315.

\section{References}

312 Adolph, A. C., \& Albert, M. R., 2014, Gas diffusivity and permeability through the firn column at

313 Summit, Greenland: measurements and comparison to microstructural properties. The Cryosphere, 8(1), 314 319-328.

315 Albert, M. R., Shultz, E. F., \& Perron, F. E., 2000, Snow and firn permeability at Siple Dome, 316 Antarctica. Annals of Glaciology, 31(1), 353-356.

317 Albert, M. R., \& Shultz, E. F., 2002, Snow and firn properties and air-snow transport processes at

318 Summit, Greenland. Atmospheric Environment, 36(15), 2789-2797.

319 Albert, M., Shuman, C., Courville, Z., Bauer, R., Fahnestock, M., \& Scambos, T, 2004, Extreme firn 320 metamorphism: impact of decades of vapor transport on near-surface firn at a low-accumulation glazed 321 site on the East Antarctic plateau. Annals of Glaciology, 39(1), 73-78. 
Beavers, G. S., \& Joseph, D. D., 1967, Boundary conditions at a naturally permeable wall. Journal of fluid mechanics, 30(01), 197-207.

Berman, A. S., 1953), Laminar flow in channels with porous walls. Journal of Applied physics, 24(9), 1232-1235.

Bolsey, 4., 2009. IDDO End of Season Report on the Thwaites Glacier - Amundsen Basin Seismic Project, unpublished.

Brandt, R. E. and S. G. Warren. 1997. Temperature measurements and heat transfer in near-surface snow at the South Pole. Journal of Glaciology, 43(144), 339-351.

Colbeck, S. C., 1983, Theory of metamorphism of dry snow. Journal of Geophysical Research: Oceans (1978-2012), 88(C9), 5475-5482.

Courville, Z. R., Albert, M. R., Fahnestock, M. A., Cathles, L. M., \& Shuman, C. A., 2007, Impacts of an accumulation hiatus on the physical properties of firn at a low-accumulation polar site. Journal of Geophysical Research: Earth Surface (2003-2012), 112(F2).

Faïn, X., Ferrari, C. P., Dommergue, A., Albert, M. R., Battle, M., Severinghaus, J., \& Boutron, C., 2009, Polar firn air reveals large-scale impact of anthropogenic mercury emissions during the 1970s. Proceedings of the National Academy of Sciences, 106(38), 16114-16119.

Flanner, M. G., \& Zender, C. S., 2006, Linking snowpack microphysics and albedo evolution. Journal of Geophysical Research: Atmospheres (1984-2012),111(D12).

Flin, F., Brzoska, J. B., Lesaffre, B., Coléou, C., \& Pieritz, R. A., 2003, Full three-dimensional modelling of curvature-dependent snow metamorphism: first results and comparison with experimental tomographic data. Journal of Physics D: Applied Physics, 36(10A), A49.

Freitag, J., Wilhelms, F., \& Kipfstuhl, S, 2004, Microstructure-dependent densification of polar firn derived from X-ray microtomography. Journal of Glaciology, 50(169), 243-250.

Granger, J., Dodds, J., \& Midoux, N., 1989, Laminar flow in channels with porous walls. The Chemical Engineering Journal, 42(3), 193-204.

Gregory, S. A., Albert, M. R., \& Baker, I., 2014, Impact of physical properties and accumulation rate on pore close-off in layered firn. The Cryosphere, 8(1), 91-105.

Guta, L., \& Sundar, S., 2010, Navier-Stokes-Brinkman system for interaction of viscous waves with a submerged porous structure. Tamkang journal of mathematics, 41(3), 217-243.

Horgan, H. J., Anandakrishnan, S., Alley, R. B., Burkett, P. G., \& Peters, L. E., 2011, Englacial seismic reflectivity: imaging crystal-orientation fabric in West Antarctica. Journal of Glaciology, 57(204), 639650.

Horhold, M. W., Albert, M. R., \& Freitag, J., 2009, The impact of accumulation rate on anisotropy and air permeability of polar firn at a high-accumulation site. Journal of Glaciology, 55(192), 625-630. 
Jayred, M, 2011. IDDO End of Season Report on the ARA RAM Drill Test at South Pole. Unpublished.

357 Kundu P. K., Cohen I. M., \& Dowling D. R., 2012, Fluid Mechanics. 5th ed. Oxford, UK. Elsevier, 115.

358 Lomonaco, R., Albert, M., \& Baker, I., 2011, Microstructural evolution of fine-grained layers through the 359 firn column at Summit, Greenland. Journal of Glaciology, 57(204), 755-762.

360 Lyons, W. C., 2009, Air and Gas Drilling Manual: Applications for Oil and Gas Recovery Wells and 361 Geothermal Fluids Recovery Wells. Gulf Professional Publishing.

362 Nicolson, K. M., 1953, Air drilling in California. Drilling and Production Practice, New York, New York. 363 American Petroleum Institute.

364 Olson, R. M., \& Eckert, E. R. G., 1966, Experimental studies of turbulent flow in a porous circular tube 365 with uniform fluid injection through the tube wall. Journal of Applied Mechanics, 33(1), 7-17.

366 Rick, U. K., \& Albert, M. R., 2004, Microstructure and permeability in the near-surface firn near a 367 potential US deep-drilling site in West Antarctica. Annals of Glaciology, 39(1), 62-66.

368 Schneebeli, M., \& Sokratov, S. A., 2004, Tomography of temperature gradient metamorphism of snow 369 and associated changes in heat conductivity. Hydrological Processes, 18(18), 3655-3665.

370 Schwander, J., Barnola, J. M., Andrie, C., Leuenberger, M., Ludin, A., Raynaud, D., and Stauffer, B, 371 1993, The age of the air in the firn and the ice at summit, greenland. J. Geophys. Res.-Atm, 98(D2):28313722838.

373 Severinghaus, J. P., Grachev, A., and Battle, M, 2001, Thermal fractionation of air in polar firn by 374 seasonal temperature gradients. Geochem. Geophy. Geosy., 2.

375 Severinghaus, J. P., Albert, M. R., Courville, Z. R., Fahnestock, M. A., Kawamura, K., Montzka, S. A., 376 Muhle, J., Scambos, T. A., Shields, E., Shuman, C. A., Suwa, M., Tans, P., and Weiss, R. F, 2010, Deep 377 air convection in the firn at a zero-accumulation site, central Antarctica. Earth Planet Sc. Lett., 293(3378 4):359-367.

379 U.S. Ice Drilling Program. Rapid Air Movement (RAM) Drill. Available at: 380 http://www.icedrill.org/equipment/ram.shtml (accessed 6 October 2014). 


\section{List of Figures}

Figure 1 (Left) Vector plot of velocity field when air enters the bottom of the borehole. Velocity magnitude is indicated by the length of the arrows. (Right) Diagram of the borehole, with the annular space, depth and radial direction labeled accordingly. Air exits the drill, enters the annular space, and then travels up the annulus or escapes out into the firn through the porous matrix. (Single Column Figure)

Figure 2 Permeability data measured from a Summit, Greenland firn core (Albert and Adolph, 2014) with curve fit and selected areas for numerical experiments indicated by the solid line. (Single Column Figure)

Figure 3 Effect of a high, low and no permeability anomaly 3a,c) Full firn permeability profile with depth with c) focusing on depths surrounding the permeability anomaly location used for these experiments (dotted - high permeability, dashed - low permeability). 3b,d) show resulting pressure plots with depth at one meter away from the borehole, inside the firn. d) focusing on depths surrounding the permeability anomaly location used for these experiments (dotted - high permeability, dashed - low permeability). 3e) Pressure up the center of the annular space of the borehole from $35 \mathrm{~m}$ to $40.5 \mathrm{~m}$. (1.5

\section{Column Figure)}

Figure 4 Effect of the depth of a high permeability anomaly. 4a) shows total pressure profile with depth for two of the eight experiments moving a one meter thick band of higher permeability to different depths indicated by the legend (solid line - band exists at 35m - 36m and dashed line - band exists from 40m 41m). 4b) graphs of integrated area under each of the eight trials' (refer to Table 1) pressure curve. 4c) Radial differential pressure from center of the annular space out to one meter within the firn matrix. 
405 Depth of the top of the permeability anomaly, for which the radial differential pressure was calculated, is 406 indicated by x-axis. (Single Column Figure)

407

408 Figure 5 Integrated firn permeability (black dots) and differential pressure (grey dots) in the borehole 409 calculated from all eight experiments where a one meter thick high permeability anomaly exists at a 410 particular depth. Depth of the top of the anomaly is indicated along the x-axis. (Single Column Figure) 


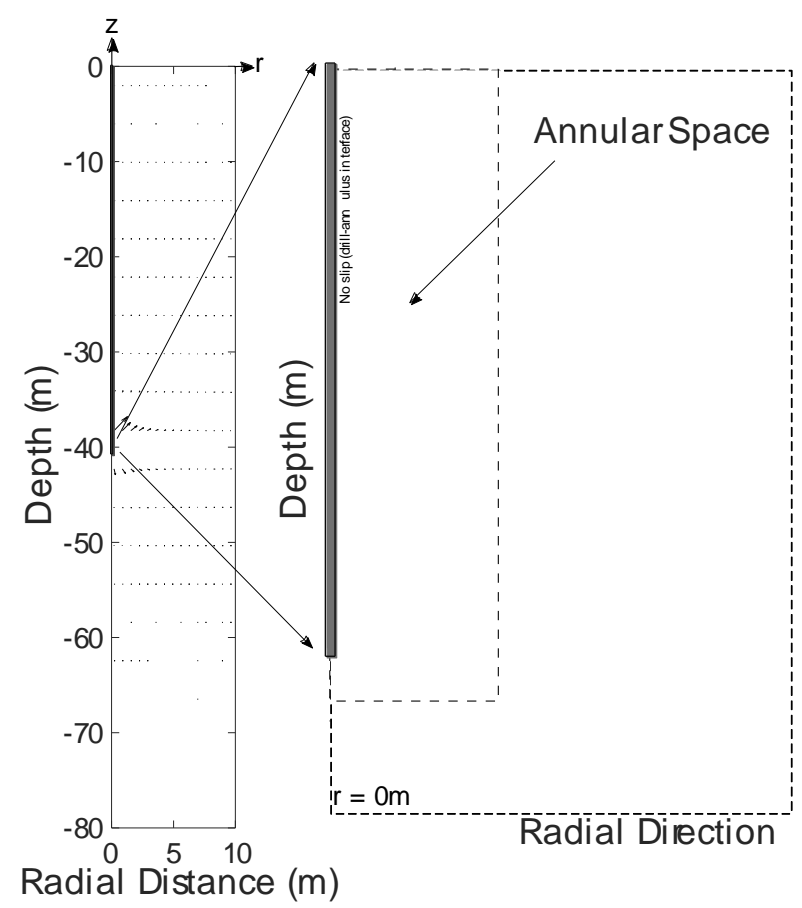

$413 \quad$ Figure 1 


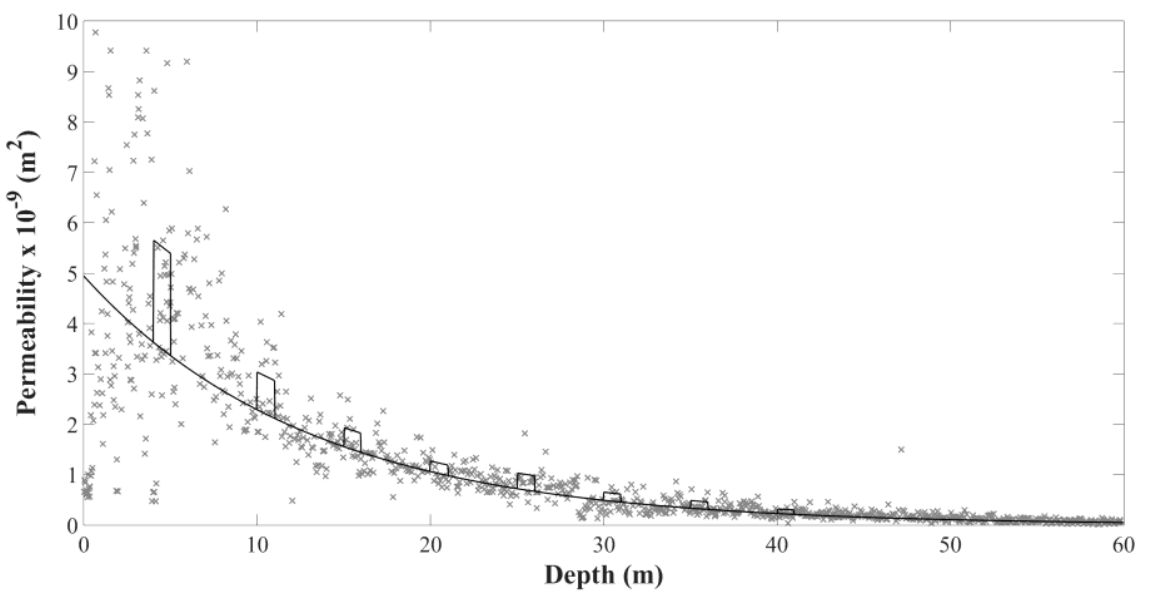

414

$415 \quad$ Figure 2 

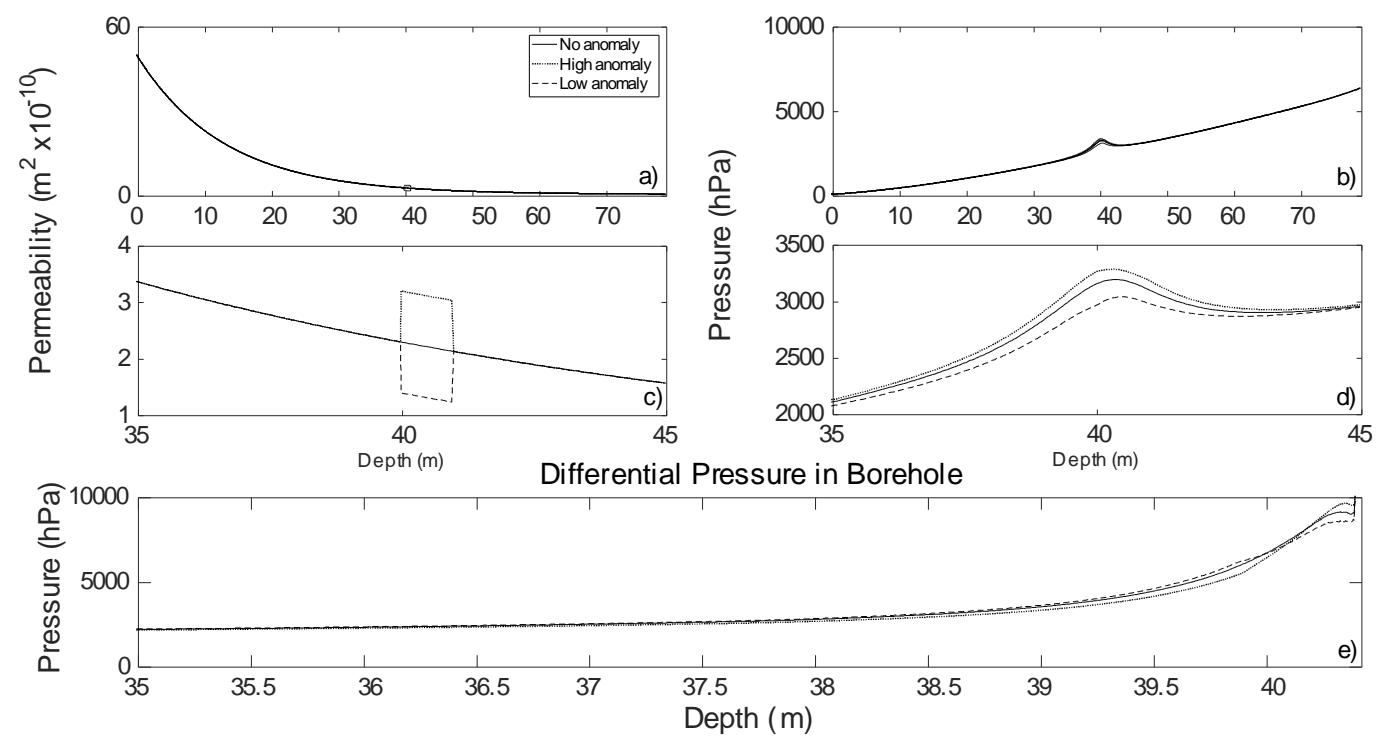

416

417 Figure 3 

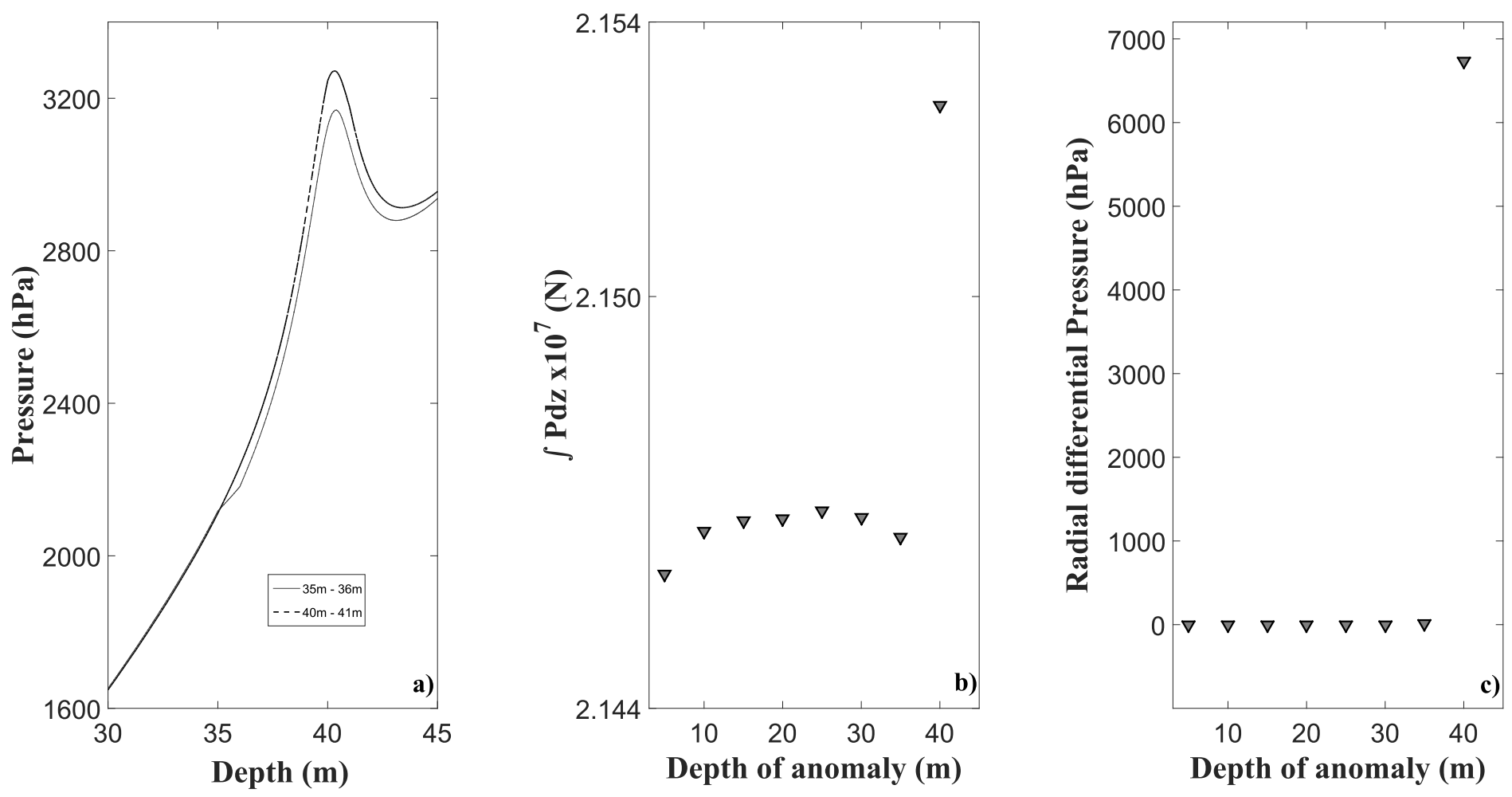

419 Figure 4 


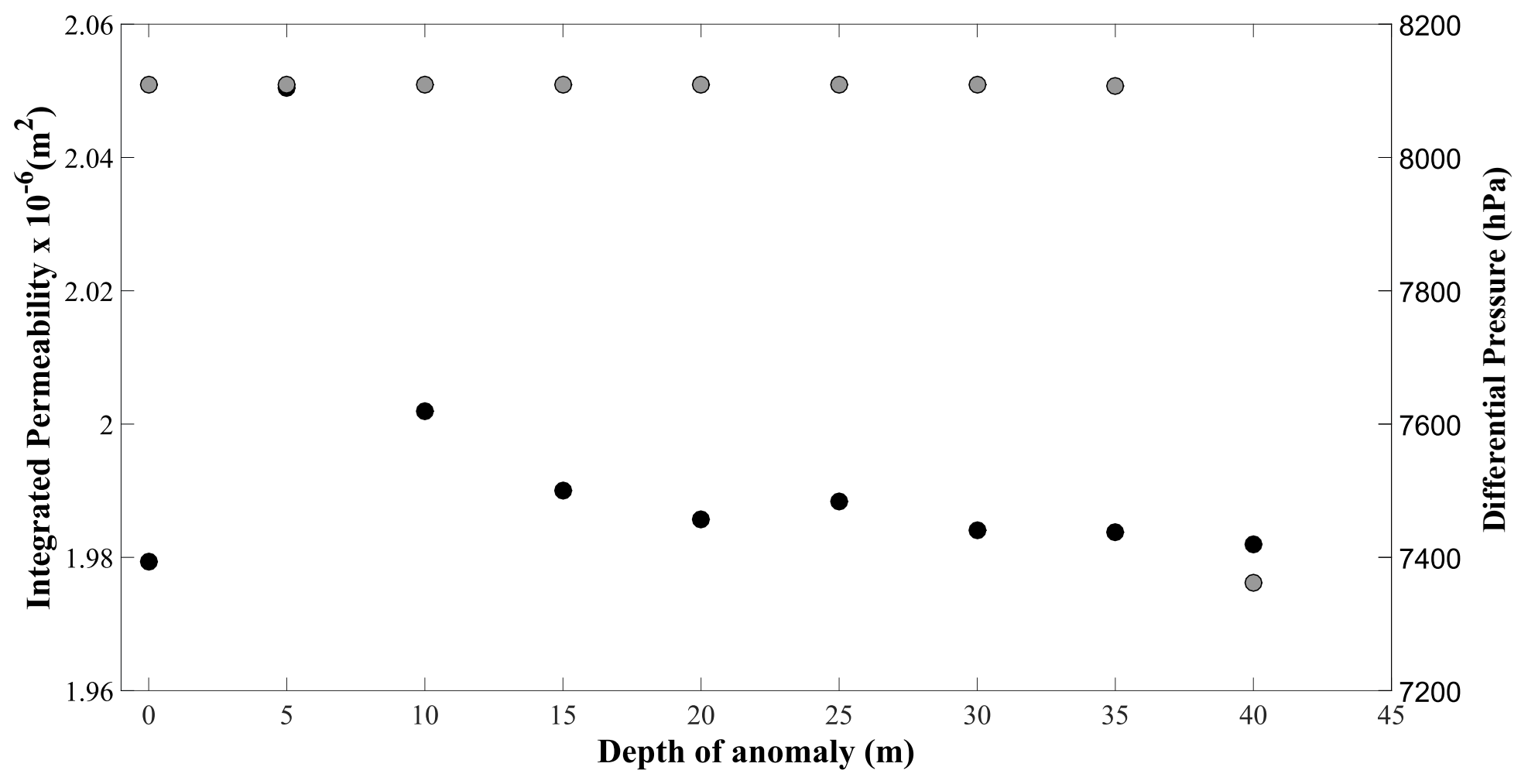

$421 \quad$ Figure 5 